\title{
Significance of ethnic disparity in cephalometric analysis in Indian population
}

\author{
Poonam Majumder ${ }^{1 *}$, Abhishek Singh ${ }^{2}$ \\ ${ }^{1}$ Consultan, ${ }^{1}$ Dept. of Orthodontics, ${ }^{2}$ Dept. of Dental Surgeon, ${ }^{1}$ Private practitioner, Agra, ${ }^{2}$ S.N.M. District hospital, Firozabad, Uttar \\ Pradesh, India
}

\begin{abstract}
Introduction: It has been a widely accepted fact that race specific norms, diagnosis and treatment planning is now a explicit need for achieving desired orthodontic treatment outcome.

Aim: The present study compares the cephalometric norms of Tweeds diagnostic triangle of the Assamese population with other Indian population s to justify this very fact.

Materials and Methods: Tweeds cephalometric study was done on the cephalograms of Assamese ethnic origin and the norm for the population was derived. These cephalometric norms for the Assamese population was compared with the established Tweeds cephalometric norms of other Indian population.

Conclusion: The statistically significant differences observed in the values of the parameters, are justify the legitimacy of the aforementioned hypothesis.
\end{abstract}

Keywords: Cephalometric norms variation, Indian population, Tweed's analysis.

\section{Introduction}

India represents an ethnological museum of diverse races, cultures, languages etc. The population of India is a colourful blend of various races of the world including the Turk Iranian, Indo Aryan, Scytho Dravidian, Aryo Dravidian, Mongol Dravidians, Mongoloids etc. It is therefore very obvious to find a vast range of normal facial types with their relative underlying skeletal and dental pattern, in this population. With the present trend of urbanisation, employment needs etc there is influx of these different populations in different regions of the country leading to a multicultural society.

Orthodontics is no longer the practice of just fitting the teeth together, but instead a specialty for prettification of the entire facial skeleton by harmonizing the whole dentition to the rest of the structures in the skull. William B. Downs had very well related the role of cephalometrics in orthodontics to that of dissection in anatomy. Both of the procedures being used to

understand better the underlying structures. ${ }^{1}$

Various studies have been conducted to better relate the standard cephalometric norms to a particular population and have observed repeatedly the significant deviation from these standard norms. The following are some of the literatures that support the hypothesis that there exists difference in the cephalometric norms of different populations.

1. Nabanita Baruah et al study of Assamese population ${ }^{10}$

2. Garcia's study' of Mexican Americans, ${ }^{5}$

3. Manan Bharat Atit et al study of Marathi population ${ }^{9}$

4. Suh's study of Koreans, ${ }^{2}$
5. Chan's study of Chinese, ${ }^{4}$

6. Drummond's study of Negroes, ${ }^{6}$

7. Nanda's study of North Indians, ${ }^{7}$

8. O.P.Kharbanda's study of North Indians ${ }^{8}$

9. Mitani's study of Japanese ${ }^{3}$

With the present changing importance towards soft tissue paradigm, orthodontists have to devote due attention to the final soft tissue outcome after orthodontic treatment. These soft tissue changes are related to the underlying hard tissue correction $^{11,12}$

The normalcy or beauty of a face, which is dependent on the soft tissues, however is a matter of perception. Different races and populations have their individual perceptions of beauty and normalcy depending on the facial features of that particular race or population. The facial profile which is normal and beautiful for one population might be perceived as abnormal or disproportionate by others $^{13,14}$. We as orthodontists play a major role in being the architect of creating a pleasing facial appearance. It is also important to remember the principles of the change to soft tissue paradigm from that of exclusive focus on the hard tissues $^{15,16}$.

The present study focuses on the difference in the skeletal patterns within the Indian population. Orthodontists now come across a wide range of patients of different racial backgrounds, having different sleletal patterns, irrespective of the place where they practise. This study thus aims to help orthodontists and other clinicians to understand this difference and utilise them to correctly correlate the patients to their respective cephalometric norms, resulting in a stable and successful orthodontic treatment outcome.

*Corresponding Author: Poonam Majumder, Dept. of Orthodontics, Private practitioner, Agra, Uttar Pradesh, India

Email address: majumderpoonam87@gmail.com

http://doi.org/10.18231/j.idjsr.2019.014 
This study aims to determine the Cephalometric norms of Tweeds Analysis for the Assamese Population and compare them with the two other Indian populations i.e. North Indian population (Kharbanda et $\mathrm{al}^{8}$ ), Maratha population(Manan Bharat Atit et $\mathrm{al}^{9}$ ).

\section{Materials and Methods}

The cephalometric radiographs of 50 subjects (23 males, 27 females) were used to study the Tweeds cephalometric norms of the Asamese population. The inclusion criteria for the selection of the sample include Assamese ethnic origin having acceptable profile with Angle Class I molar relationship. The exclusion criterion included history of previous orthodontic treatment, gross carious lesion, periodontal disease, history of facial trauma etc. The cephalometric norms for Tweeds analysis of the North
Indian population has been derived from the article published by O.P.Kharbanda et $\mathrm{al}^{8}$ and that of the Maratha population has been derived from the article published by Manan Bharat et al. ${ }^{9}$ The Tweeds cephalometric norm for Assamese population was derived from the study published by P.Majumder et al. ${ }^{17}$

The following cephalometric parameters were used to do the Tweeds analysis:

1. Frankfort Mandibular plane Angle (FMA mean value 25 degree)

2. Frankfort Mandibular Incisal Angle (FMIA mean value 65 degree)

3. Incisor Mandibular Plane Angle (IMPA mean value 90 degree)

\section{Results}

Table 1: Descriptive statistics for the cephalometric measurements for Assamese population in this study

\begin{tabular}{|c|c|c|c|c|c|}
\hline Parameter & Mean & SD & SE & Minimum & Maximum \\
\hline FMA & 26.54 & 3.70 & 0.70 & 18 & 34 \\
\hline FMIA & 56.61 & 6.30 & 1.19 & 45 & 68 \\
\hline IMPA & 97.04 & 6.93 & 1.31 & 85 & 111 \\
\hline
\end{tabular}

Table 2: Mean values of three population

\begin{tabular}{|c|c|c|c|c|c|}
\hline Parameter & \multicolumn{2}{|c|}{ Assamese } & North India & \multicolumn{2}{c|}{ Marathi } \\
\hline & Female & male & & Female & Male \\
\hline FMA & 26.54 & 23.95 & $23-49$ & 23.9 & 20.8 \\
\hline FMIA & 56.61 & 56.68 & 53.87 & 57.2 & 63.9 \\
\hline 97.04 & 97.04 & 99.36 & 101.7 & 98.20 & 95.3 \\
\hline
\end{tabular}

Table 3: Comparative statistics of Tweeds cephalometric norms between Assamese and Maratha male population.

\begin{tabular}{|c|c|c|c|c|}
\hline Parameter & Mean & SD & SE & p value \\
\hline FMA & 23.9545 & 5.1221 & 1.092 & 0.0088 \\
\hline FMIA & 56.6818 & 7.5302 & 1.6054 & 0.0002 \\
\hline IMPA & 99.3636 & 6.2453 & 1.3315 & 0.0061 \\
\hline
\end{tabular}

Table 4: Comparative statistics of Tweeds cephalometric norms between Assamese and Maratha female population

\begin{tabular}{|c|c|c|c|c|}
\hline Parameter & Mean & SD & SE & p value \\
\hline FMA & 26.5357 & 3.7017 & 0.6996 & 0.0008 \\
\hline FMIA & 56.6071 & 6.2957 & 1.1898 & 0.6223 \\
\hline IMPA & 97.0357 & 6.9348 & 1.3106 & 0.3822 \\
\hline
\end{tabular}

Table 5: Comparative statistics of Tweeds cephalometric norms between Assamese and North Indian population.

\begin{tabular}{|c|c|c|c|c|}
\hline Parameter & Mean & SD & SE & p value \\
\hline FMA & 26.5357 & 3.7017 & 0.6996 & 0.0008 \\
\hline FMIA & 56.6071 & 6.2957 & 1.1898 & 0.6223 \\
\hline IMPA & 97.0357 & 6.9348 & 1.3106 & 0.3822 \\
\hline
\end{tabular}




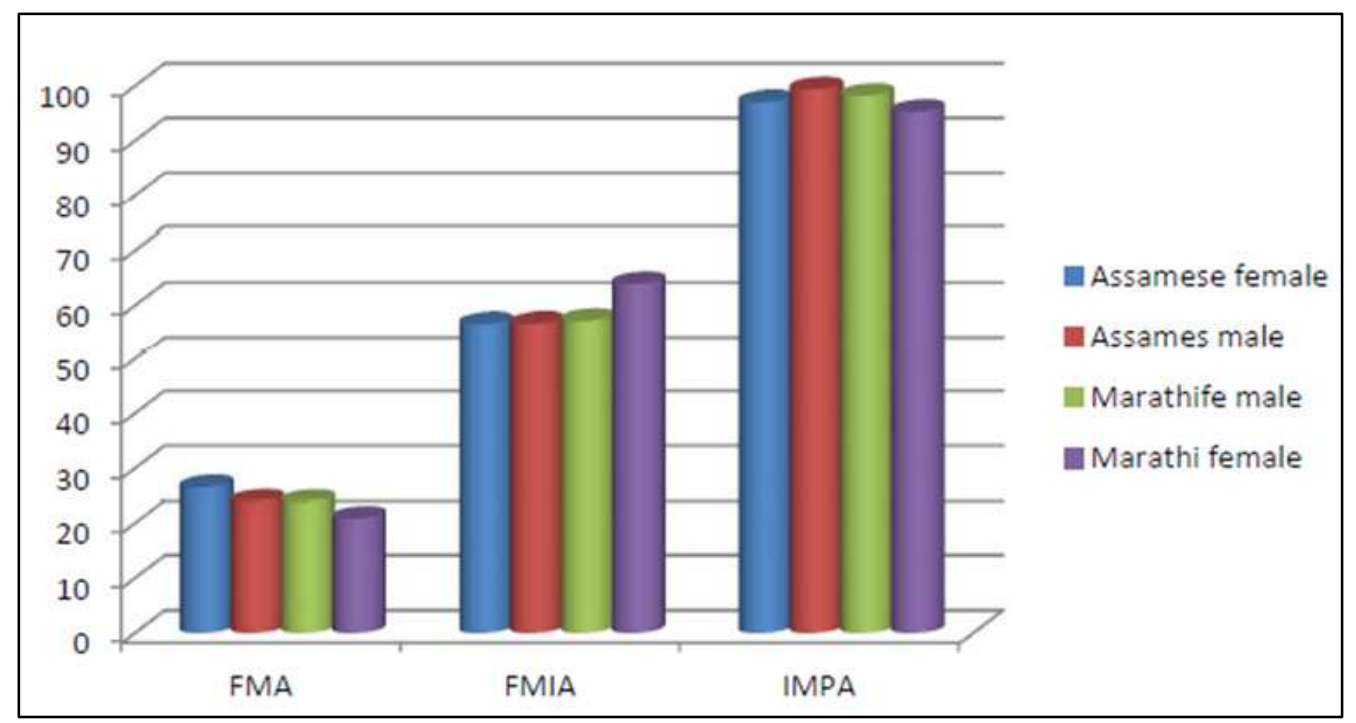

Graph 1: Comparison of Tweeds cephalometric values of Assamese and Marathi male and female.

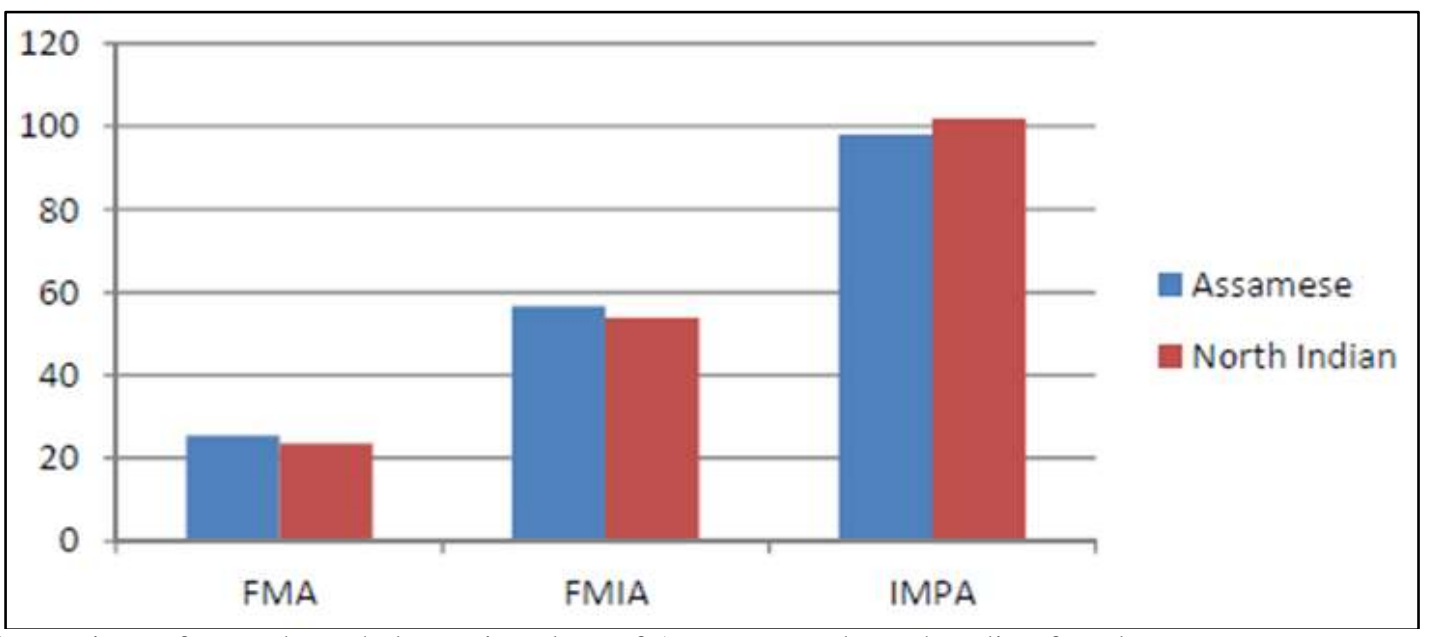

Graph 2: Comparison of Tweeds cephalometric values of Assamese and North Indian female.

\section{Discussion}

\section{Frankfort Mandibular Plane Angle (FMPA)}

Comparison between mean FMPA of Assamese ${ }^{17}$ with North Indians ${ }^{8}$ and Marathas ${ }^{9}$

The mean value of Frankfort Mandibular Plane Angle of the Assamese population is $25.4^{\circ}$ which is greater than that of North Indians and the Marathas, and this difference is statistically significant $(\mathrm{p}<0.01)$.This indicates the Assamese population has a steeper mandible and more vertical growth pattern as compared to the North Indian and Maratha populations.

\section{Incisor Mandibular Plane Angle (IMPA)}

Comparison between mean IMPA of Assamese ${ }^{17}$ with North Indians ${ }^{8}$

The mean value of Incisor Mandibular Plane Angle for the Assamese population is lesser than the mean for North Indian population and this difference is highly significant statistically $(\mathrm{p}<0.001)$. This means that Assamese population have more upright lower incisors as compared to that of the North Indian population. ${ }^{8}$

Comparison between mean IMPA of Assamese ${ }^{17}$ with Marathas ${ }^{9}$

The Assamese and Maratha females have similar inclination of the lower incisors in relation to the mandibular plane( $p>0.05)$.However in case of the males the difference was significant $(p<0.05)$ which signifies more proclined lower incisors of Assamese male as compared to the Maratha males.

\section{Frankfort Mandibular Incisor Angle (FMIA)}

Comparison between mean FMIA of Assamese ${ }^{17}$ with North Indian ${ }^{8}$

There is a statistically significant mean difference $(p<0.05)$ in the value of FMIA between the two population. Assamese population has slightly more upright lower 
incisors in relation to the Frankfort plane as compared to that of the North Indian population.

\section{Comparison between mean FMIA of Assamese ${ }^{17}$ with Marathas ${ }^{9}$}

Assamese and Maratha females have similar inclination of the lower incisors in relation to the mandibular plane. However there was high statistically significant difference $(p<0.01)$ in the male values which indicates that the Assamese male have more proclined lower incisors in relation to the mandibular plane as compared to the Maratha males.

The above observations further strengthen the theory of racial variations in cephalometric norms which have been stated repeatedly by various authors in their studies viz Nanda's study of North Indians, ${ }^{7}$ O.P.Kharbanda's study of North Indians ${ }^{8}$, Manan Bharat Atit et al study of Marathi population ${ }^{9}$, Nabanita Baruah et al study of Assamese population ${ }^{10}$ etc.

\section{Conclusion}

Tweed's cephalometric analysis is a simple yet very clinically significant diagnostic method to determine the direction and pattern of the growth of the lower face. The present study uses this diagnostic tool to bring into attention the normal values of Tweed's cephalometric norms of the individual population and compares these individualized norms. Upon comparison varying amount of statistically significant differences among the cephalometric parameters of the three populations i,e. Assamese, North Indian, Maratha Indian.

This study has not used the various other cephalometric parameters routinely used in orthodontic diagnosis and treatment planning, because the aim of the study is not to determine the difference in each such parameter, rather the aim is to prove the theory that there exists variations in the skeletal pattern between the various populations within India which is proved by the statistically significant differences between the parameters.

The recent use of various softwares for cephalometric analysis has reduced the time needed and the inherent manual errors of diagnosis. While we embrace the newer advances we also have to keep our feet deeply rooted into the basic foundations of diagnosis and treatment planning and hence remember the differences that exist in the cephalometric parameters between the individual populations. This will help the clinician to correctly correlate the skeletal or dental pattern of a patient to his/her individualized population norms, and then diagnose the underlying problem and structure a treatment plan which will be in accordance to the normal cephalometric parameter of the particular population. A good treatment plan will ultimately help to achieve the Andrews principles of functional occlusion, esthetic balance and stability, in the final treatment outcome.

\section{Source of Funding}

None.

\section{Conflict of Interest}

None.

\section{Reference}

1. Willian B. Downs, M.S.Aurora. The role of cephalometrics in orthodontic case analysis and diagnosis.Presented at the Fortyfourth Annual Meeting of the American Association of Orthodontists, Columbus, Ohio, 1948;26-29.

2. Suh C-H. Roentgenographic cephalometric study on the teeth and skull. J Korean Modem Med 1967;6:515-27.

3. Mitani S. A roentgenocephalometric study of seventeen-year old Japanese using several analyses [Master's thesis]. Loyola LJniversity School of Dentistry, 1980.

4. Chan GH.K. A Cephalometric appraisal of the Chinese(Cantonese). Am J Orthod 1975;61:279-85

5. Garcia CJ. Cephalometric evaluation of Mexican Americans using the Downs and Steiner analyses. Am J Oitiiod 1975;68:67-14.

6. Drummond R A. A determination of cephalometric norms for Negro race. Am J Orthod 1968;54:670-82.

7. R. Nanda, R.S. Nanda, Cephalometric study of the Dentofacial complex of the North Indians. The Angle Orthodontist 1969:39:1

8. Kharbanda OP, Sidhu SS, Sundaram KR. Cephalometric profile of north Indians: Tweed's analysis. Int J Orthod, FallWinter 1991;29(3-4):3-5.

9. Manan Bharat Atit, Sonali Vijay Deshmukh,Jayesh Rahalkar,Vijay Subramanian, Charudatt Naik, Milind Darda. Mean values of Steiner, Tweed, Ricketts and McNamara analysis in Maratha ethnic population: A cephalometric study. APOS Trends Orthodontics 2013;3(5).

10. Nabanita Baruah, Mitali Bora "Cephalometric evaluation based on Steiners Analysis on young adults of Assam". J Indian Orthod Soc 2009;43.

11. Downs WB. Variations in facial relationships: their significance in treatment and prognosis. Am J Orthod 1948;34:812-40

12. Steiner CC. Cephalometrics for you and me. Am J Orthod 1953; 39:729-55.

13. Wylie. Quoted by S E Coben. The integration of facial skeletal variants. Am J Ortho 1955;41:407-33

14. Sassouni V. A roentgenographic cephalometric analysis of cephalo facial-dental relationships. Am J Orthod 1955;41:73564 .

15. Burstone C J. Integumental Contour and Extension Patterns. Angle Orthod 1959;29(2):93-104.

16. Bowker W.D. and Meredith H.V. A metric analysis of facial profile. Angle Orthod 1959;29:149

17. P.Majumder, Sharma M, Chokotiya H, Dasgupta M, Chanu NI. Cephalometric evaluation of the Assamese Young Adults using Tweeds analysis. Int Dent J Student Res 2018;6(2);26-30.

How to cite this article: Majumder P, Singh A, Significance of ethnic disparity in cephalometric analysis in Indian population. Int Dent J Student Res 2019;7(3):56-9. 